Journal of Nepal Geological Society, 2019, vol. 58 (Sp. Issue), pp. 21-28

DOI: https://doi.org/10.3126/jngs.v58i0.24570

\title{
Electrical resistivity survey in the investigation of hydrogeological condition of Sylhet-Sunamganj Haor area, Bangladesh
}

\author{
*A.S.M. Woobaidullah1, S.M. Shahnewaz², Md. Munirul Islam², Md. Kamrul Islam², and Md. Zakir Hossain ${ }^{1}$ \\ ${ }^{1}$ Geology Department, Dhaka University, Dhaka 1000, \\ 2Institute of Water Modeling, House\#496, Rd\#32, Dhaka 1206, Bangladesh \\ *Corresponding author: woobaid.du@gmail.com
}

\begin{abstract}
Bangladesh depends on the ground water resources to meet domestic and agricultural demands. Electrical Resistivity Sounding survey, borehole lithologs and the water quality data of the area have been analysed for the assessment of subsurface hydrogeological condition of the study area, located in north eastern region of Bangladesh. Hydrogeological data are needed to determine the basic parameters required for the characterization of aquifer. VES can provide subsurface information related to groundwater condition in conjunction with borehole and water quality information.

Resistivity soundings were carried out to establish the characteristics of the aquifer in the study area. Results of resistivity soundings and borehole data reveal that the subsurface formations are made up of clay, silty clay, clayey sand, fine, medium and coarse sands. The hydrostratigraphic unit of the study area comprises of three aquifer systems separated by aquitards. Aquifer-1 known as shallow aquifer, shows thickness in the range from $4 \mathrm{~m}$ to $104 \mathrm{~m}$. Maximum thickness of Aquifer-1 is about $104 \mathrm{~m}$ at Atpara, Kishoreganj and minimum thickness is about $4 \mathrm{~m}$ at Madan, Netrokona. Aquifer-2 shows thickness variation from $3 \mathrm{~m}$ to $135 \mathrm{~m}$. Maximum thickness of Aquifer-2 is about $135 \mathrm{~m}$ at Madhabpur, Habiganj and minimum thickness is about $3 \mathrm{~m}$ at Bajitpur, Kishoreganj. Base of Aquifer-3, the deep aquifer could not be identified. Maximum depth of the upper boundary of this unit is about $171 \mathrm{~m}$ at Madhabpur, Habiganj and minimum depth is about $100 \mathrm{~m}$ at Mohanganj, Netrokona. At Madan, Netrokona low resistivity value of about 7 ohm$\mathrm{m}$ below $107 \mathrm{~m}$ depth is found against a fine to medium sand layer suggesting saline formation water.
\end{abstract}

Keywords: Resistivity, Hydrogeological condition, Aquifer, Aquitard

Paper Received: 24 Dec 2018

Paper Accepted: 2 Apr 2019

\section{INTRODUCTION}

Geophysics is the application of physics in Geology. Geophysical investigations are taking measurements at or near the earth surface which are influenced by the internal physical properties. Water is the most important constituent of life. Every human activity requires water. Normally, the easiest and most convenient way to meet the public demand for water are rivers and lakes, less than 0.01 percent of the world's total water and less than two percent of the world's fresh water. Groundwater, on the other hand accounts for about ninety-eight percent of the world's reasonably constant supply, which is not likely to dry up under natural conditions in crust to the surface sources. The Department of Bangladesh Haor and Wetland Development (DBHWD) is mandated to ensure overall coordination and monitoring for integrated development of haors and wetlands that will holistically address the problems related to water resources, agriculture, fisheries, livestocks, ecology and biodiversity. Following the recommended strategy of the Haor Master Plan, DBHWD is now giving emphasis on promoting investigation and expansion of groundwater irrigation which has been formulated to facilitate improved and sustainable management of surface water and groundwater resources for agricultural use in haor area through an integrated mathematical modeling study. Under this program a study covering Habiganj, Maulvibazar, Sylhet, Kishoreganj, Netrokona and Sunamganj districts is (Fig. 1) proposed to explore the availability of both surface water as well as groundwater resources to develop future irrigation expansion plan for proper management of water resources in an integrated manner. The major activities to accomplish the study objectives are hydrogeological investigations, assessment of water resources using mathematical modeling and development of an Interactive Information System (IIS) development by using the state of art technology. The hydrogeological investigations include exploratory drilling, construction of production tube wells, long term aquifer tests, installation and monitoring of groundwater level, geophysical survey, seepage and percolation measurements and water quality sampling and analysis. The modeling works include development, calibration and validation of surface water and groundwater interaction model for the study area. The main objective of the geophysical investigation is to delineate aquifer system of the study area (Woobaidullah, 1994, 1996, 2011). The specific objectives of the investigation are: a) to identify the different geological layers along with its vertical and horizontal extent 


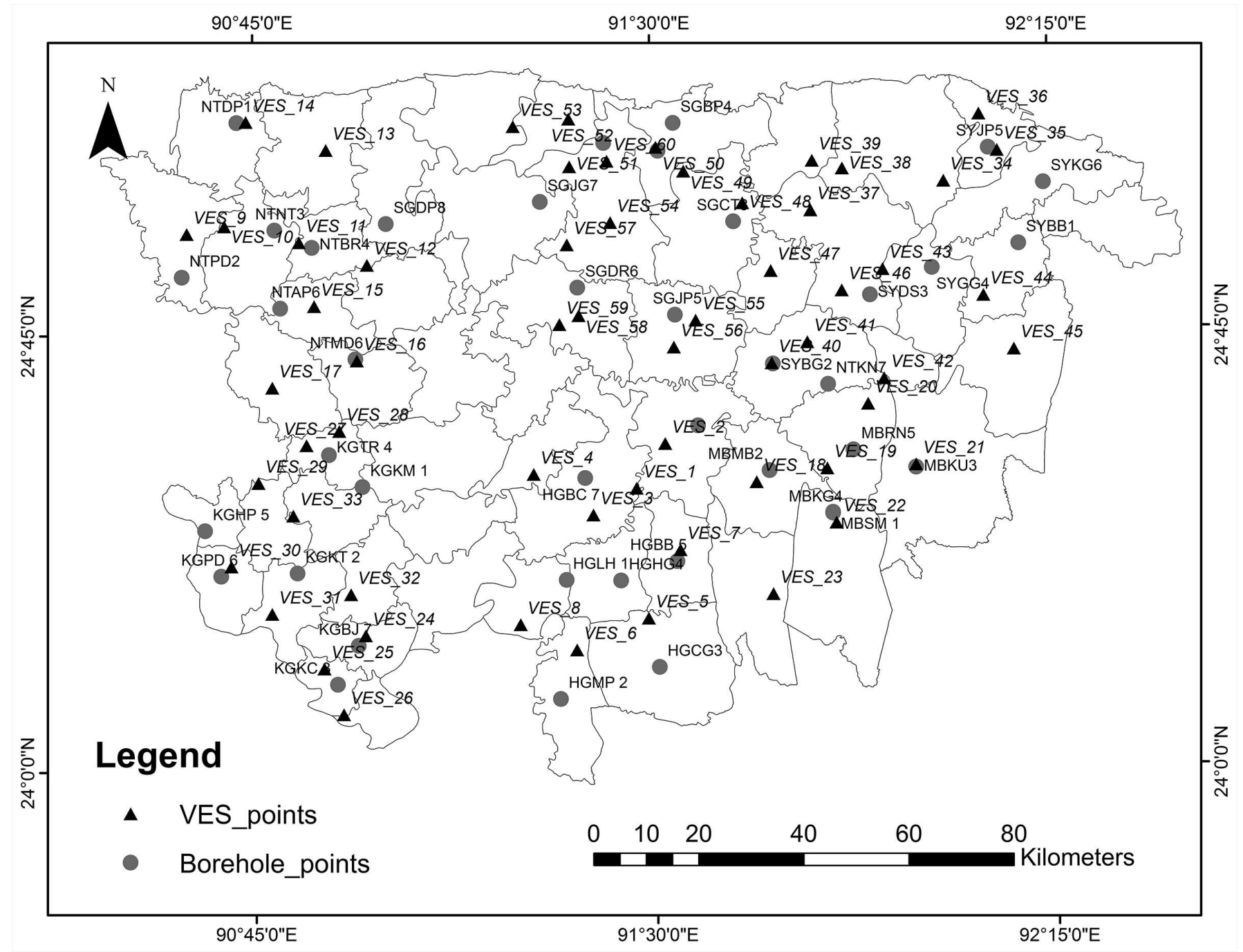

Fig. 1: Location Map of the study area (North eastern part of Bangladesh)

minimum up to the depth of 200 meters within the study area, and b) to identify the potential aquifers minimum up to the depth of 200 meters along with their depth, extent and thickness.

Ice bergs of Antarctica and North Polar Region are melting rapidly due to global warming. According to IPCC if $1 \mathrm{~m}$ of sea level rises in 2050,17\% of our coastal area will be inundated. $10 \%$ of rice $30 \%$ of wheat cultivation land will be totally destroyed. That is why we should concern on our inland area to rise up cultivation. North eastern area of Bangladesh is comparatively higher in elevation than the coastal area. Crop cultivation should be increased in this area due to this upcoming hazard. For this reason, geophysical and hydrogeological research work have been conducted in this region.

\section{METHODOLOGY}

Geo-electrical resistivity survey has long been used for geo-engineering studies and the method is found to be very successful (Serres, 1969; UNDP, 1982; Woobaidullah, 1998). In resistivity method, artificially generated electric currents are introduced into the ground and the resulting potential differences are measured at the surface (Woobaidullah, 2014). The arrangement of current and potential electrodes on or in the ground for the purpose of making an electrical survey is called electrode configuration. The current electrodes are generally placed on the outside of the potential electrodes. Based on the position of current or potential electrodes and variation in distance between them, a variety of electrode configurations are possible of which some are mentioned below: 1) Wenner configuration 2) Schlumberger configuration and 3) Dipoledipole configuration. The electrical resistivity survey involves electrical sounding using Schlumberger configuration with McOHM (Model-2115) resistivity meter. Schlumberger proposed this configuration in 1916. This is the only array to rival the Wenner in availability of interpretational material. The Schlumberger configuration is widely used in measuring the earth resistivities, which is designed to measure approximately the potential gradient. In this array four electrodes are placed symmetrically from the center, where the outer two electrodes are current electrodes. The current electrodes $(\mathrm{A} \& \mathrm{~B})$ are spaced much further apart then the potential electrodes $(M \& N)$. The distance between the potential electrodes is $1 / 5$ to $1 / 10$ th of the 


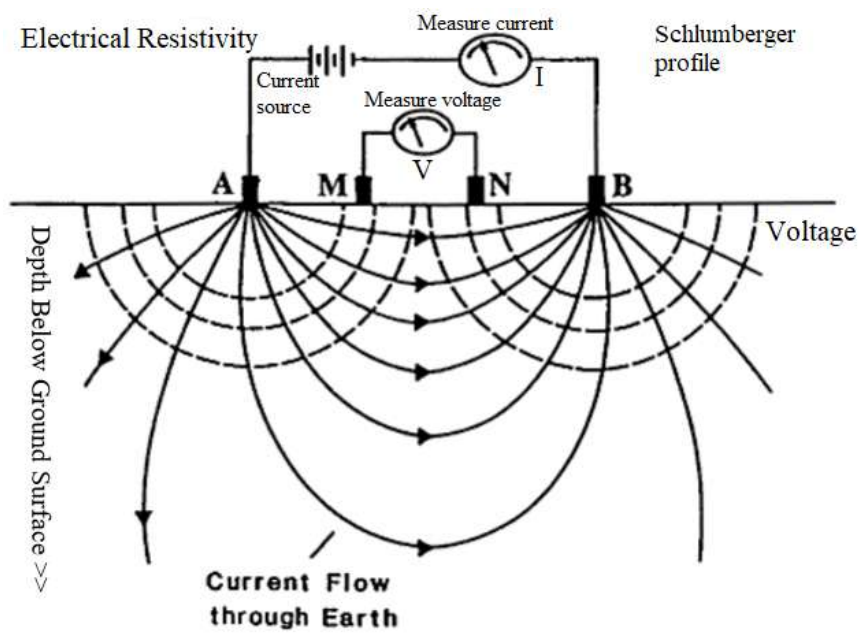

Fig. 2: Schlumberger Configuration

current electrodes.

In depth probing the potential electrodes remain fixed while the current electrodes spacing is expanded symmetrically about the center of the spread. For large values of current electrode separation, it may be necessary to increase the potential electrode separation in order to maintain a measurable potential. In case of lateral exploration, the electrode spacing remains fixed and the whole array is moved along the line in suitable steps (Fig. 2). For Schlumberger configuration the apparent resistivity is determined by the following equation:

$$
\begin{aligned}
& \text { ra = 2pi (L2-12)/21 . deltaV/I } \\
& \begin{aligned}
& \text { Where, } \mathrm{L}=\text { half of the current electrode separation. } \\
& \mathrm{l}=\text { half of the potential electrode separation. } \\
& \text { delta } \mathrm{V}=\text { measured potential difference } \\
& \mathrm{I}=\text { supplied amount of current. }
\end{aligned}
\end{aligned}
$$

Vertical Electrical Resistivity Soundings (VES) were carried out in the study area with an objective to follow the subsurface lithology variation, determine aquifer geometry, and possible thickness and extension of the aquifer and aquitard.

Sixty VES of Schlumberger Configuration with $600 \mathrm{~m}$ $(\mathrm{AB} / 2=300 \mathrm{~m})$ spread were planned to execute along the profiles in the study area. The resistivity measuring equipment "Resistivity Meter" for the survey was kept at the center of the array. The station location as given by the client was random but covering the whole study area. The layout was done along a straight line from the centre. The half of the current electrode separation $(\mathrm{AB} / 2)$ as selected was $1 \mathrm{~m}, 2 \mathrm{~m}, 4 \mathrm{~m}, 6 \mathrm{~m}, 8 \mathrm{~m}, 10$ m, $12 \mathrm{~m}, 15 \mathrm{~m}, 20 \mathrm{~m}, 25 \mathrm{~m}, 30 \mathrm{~m}, 50 \mathrm{~m}, 60 \mathrm{~m}, 80 \mathrm{~m}, 100 \mathrm{~m}$, $120 \mathrm{~m}, 150 \mathrm{~m}, 200 \mathrm{~m}, 250 \mathrm{~m}$ and $300 \mathrm{~m}$ in each side of the station. The potential electrode spacing was selected depending on the measurement of potential difference. The potential electrode spacing was $0.5 \mathrm{~m}, 1 \mathrm{~m}, 2 \mathrm{~m}, 5 \mathrm{~m}, 10 \mathrm{~m}$ and $20 \mathrm{~m}$ in each side of the centre. If large variations were observed in the subsequent values of apparent resistivity measurements were repeated to find the steadiness in the measurements.

\section{INTERPRETATION}

The sounding data were plotted in the software namely IX1D to see the smoothness of the data as well as interpretation. The final model obtained through software-based matching was taken to be the subsurface united geo-electric model of VES point (Fig. 3). This model was then compared and calibrated to the bore log data on or close to the VES point to obtain the final geo-electric model (Figs. 4, 5).

For the comparison between bore log and vertical electrical sounding (VES), it is essential that the location of the bore hole is on very close to the VES location point. It has been realized that for making a comparison using a generalized lithologic succession, resistivity sounding is a quite efficient method and therefore it can be considered as a good means for the evaluation subsurface geological condition particularly in terms of aquifer, aquitard etc.
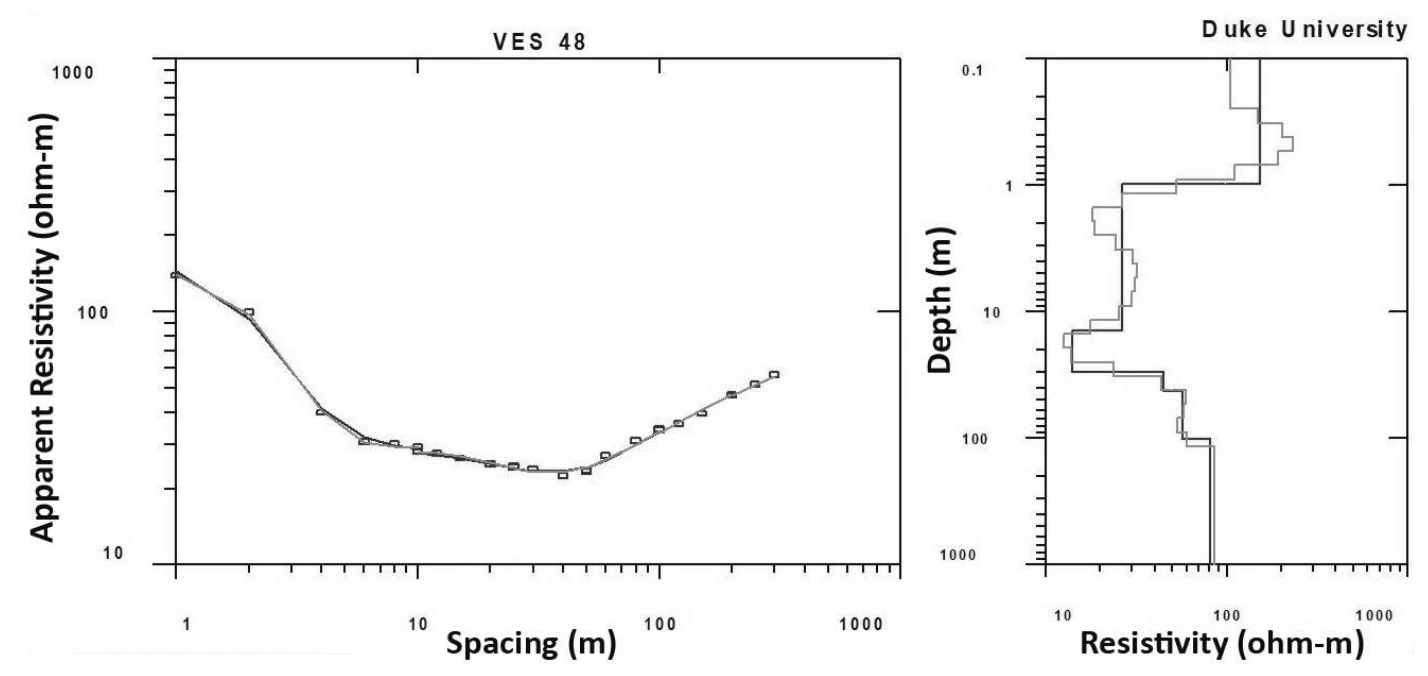

Fig. 3: Sounding Curve of VES 48 (Left) and the respective subsurface geoelectric model (Right) 

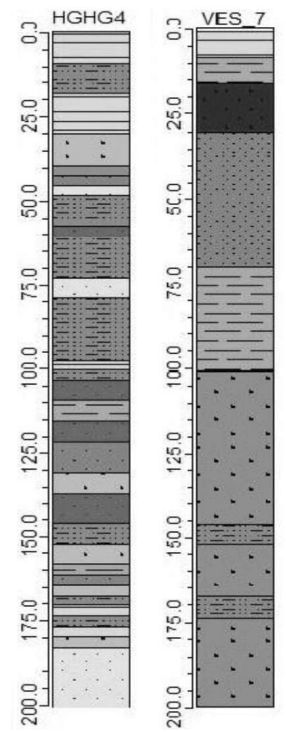
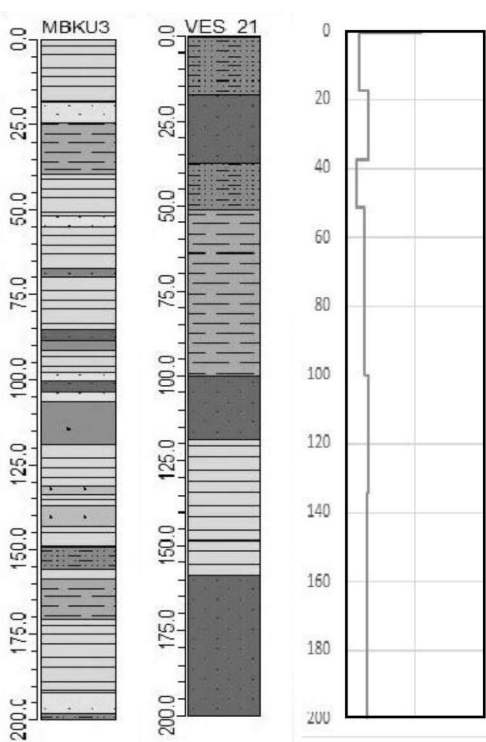

Fig. 4: Comparison between Lithology column of borehole No. HGHG4 and Geo-electric model of VES-7

After comparing the VES and bore log data the following resistivity range against different rock types have been found (Table 1).

Vertical Electrical sounding result is more or less close to the actual subsurface geologic picture that was derived from borehole data. Although for an average (gross) value of sub surface layer resistivity is a useful method, but for minute units and sophisticated observations, borelog data is needed.

\section{RESULTS}

Interpretation results of the VES curves suggest non uniformity in the distribution of resistivity in vertical as well as lateral directions. The top soil of the area is characterized by resistivity variation from $15.847 \mathrm{ohm}-\mathrm{m}$ to $662.71 \mathrm{ohm}-\mathrm{m}$ and the thickness varies from $0.35 \mathrm{~m}$ to $4.25 \mathrm{~m}$. The large range of resistivity variation is related to nature and wetness of the top soil. Dry and hard compacted silty soil shows higher resistivity while clayey moistured soil shows lower resistivity. Below the top soil layer, clay or silty clay layer occurs which are called Aquitard and the resistivity value ranging from $11 \mathrm{ohm}-\mathrm{m}$ to $24 \mathrm{ohm}-\mathrm{m}$. Higher resistivity in some VES location is probably due to the presence of silt particles in this clay layer. Below this clay layer there lies sandy layer which is called Aquifer showing resistivity value varying from $25 \mathrm{ohm}-\mathrm{m}$ to 163.54 ohm-m. Considering the resistivity value it can be said that the grain size of this sand layer is composed of fine to very fine sands, fine to medium sand, fine sand (31-40 ohm-m), medium sand (41-80 ohm-m) and coarse sand (>80 ohm-m). Borelog data also confirms the sand size variation in the sequence. When sandy layer contains saline water (at Madan, Netrokona saline water found below $107 \mathrm{~m}$ depth) it shows low resistivity value Fig. 5: Comparison between Lithology column of borehole
MBKU 3 and Geo-electric model of VES-21

near about clay resistivity or even less resistivity value. In this case we need direct information from bore log data either the layer sandy or clay.

\section{Geoelectric sections}

The geo-electric sections across the stations generally shows the different subsurface layers and the depth at which they are encountered during the course of investigation in relation to layer resistivities. The geo-electric section was drawn across different directions that approximately WE, SW-NE and, SE-NW. The section has five layers at the VES points excluding the upper most top soil.

\section{Interpretation of geoelectric cross-section of the study area along $A-A^{`}$}

Geolelectric cross section along A-A' (Fig. 7) has been executed from west to east corner of the study area. 3 aquifer systems have been found in the study area. Surface layer is composed of silty clayey soil and the following layer is Aquitard1. This Aquitard-1 is relatively thin in the western part and slightly thick in the middle part of the cross section. The following layer is Aquifer-1 which is thick in the western and thinner in the middle and in the eastern part. Aquifer- 1 is underlain by a thin Aquitard-2 which is continuous throughout the cross section. The following layer Aquifer-2 is thick in the middle part of the section. Aquitard-3 is the following layer which is slightly thick in the western and eastern parts, but in the middle part Aquitard-3 is very thin and hard to show in the cross section. The deepest identified layer is Aquifar-3 thickness of which couldn't be identified. It may continue below our observation depth. 


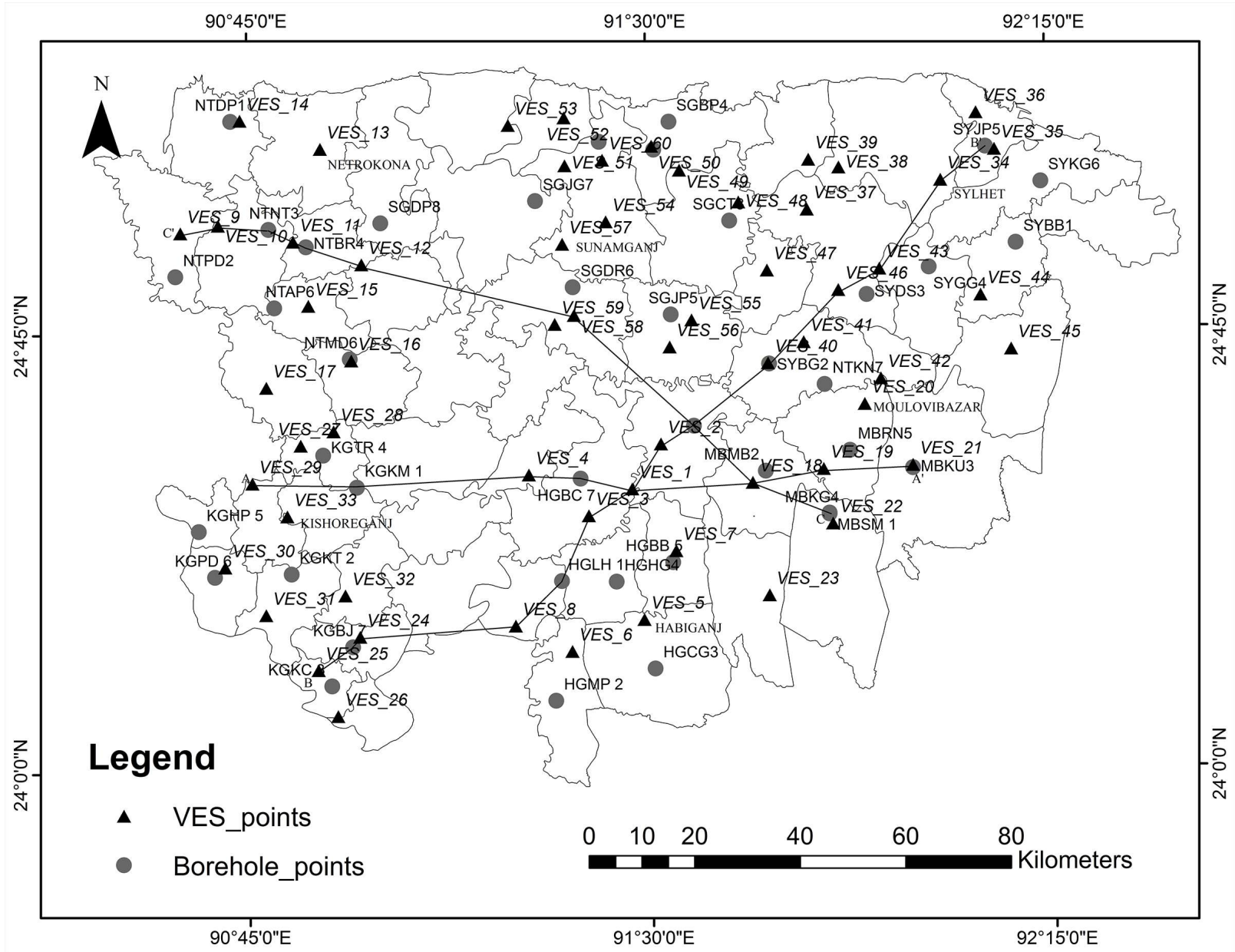

Fig. 6: Map showing the lines of cross-sections in the study area

\section{Interpretation of geoelectric cross-section of the study area} along $B-B$

Geoelectric cross section along B-B`(Fig. 8) has been executed from SW-NE corner of the study area. The top layer is composed of silty clayey soil and is followed by Aquitard1. Aquitard-1 is thin in the middle part of the cross section.
Aquitard-1 is underlain by Aquifer-1, which is thick in the middle part of the section. The following hydrostratigraphic unit is Aquitard-2, which is relatively thin in the middle part of the cross section. Aquifer-2 with a more or less uniform thickness is overlain by Aquitard-2. Aquifer-2 is underlain by Aquitard3 , which is thinner than the Aquitard-2 and in the middle it is very thin and hard to show in the cross section. The deepest

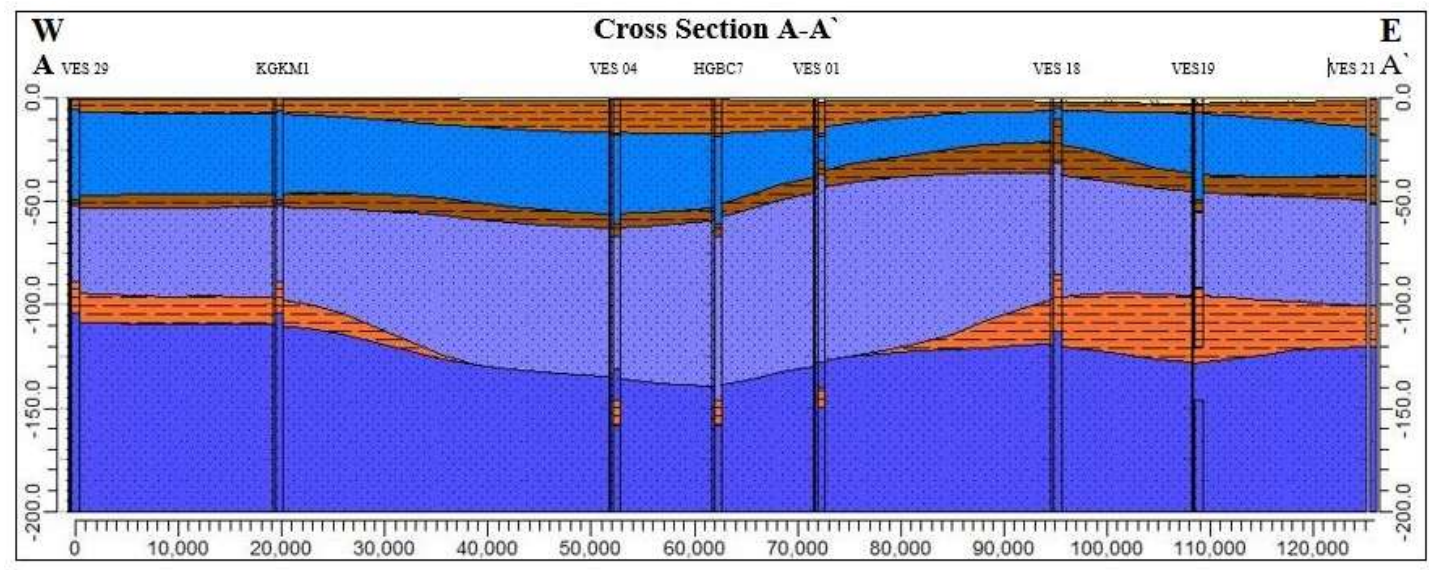

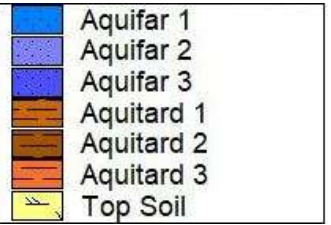

Fig. 7: Geo-electric cross-section along line A-A` of the study area with legend 


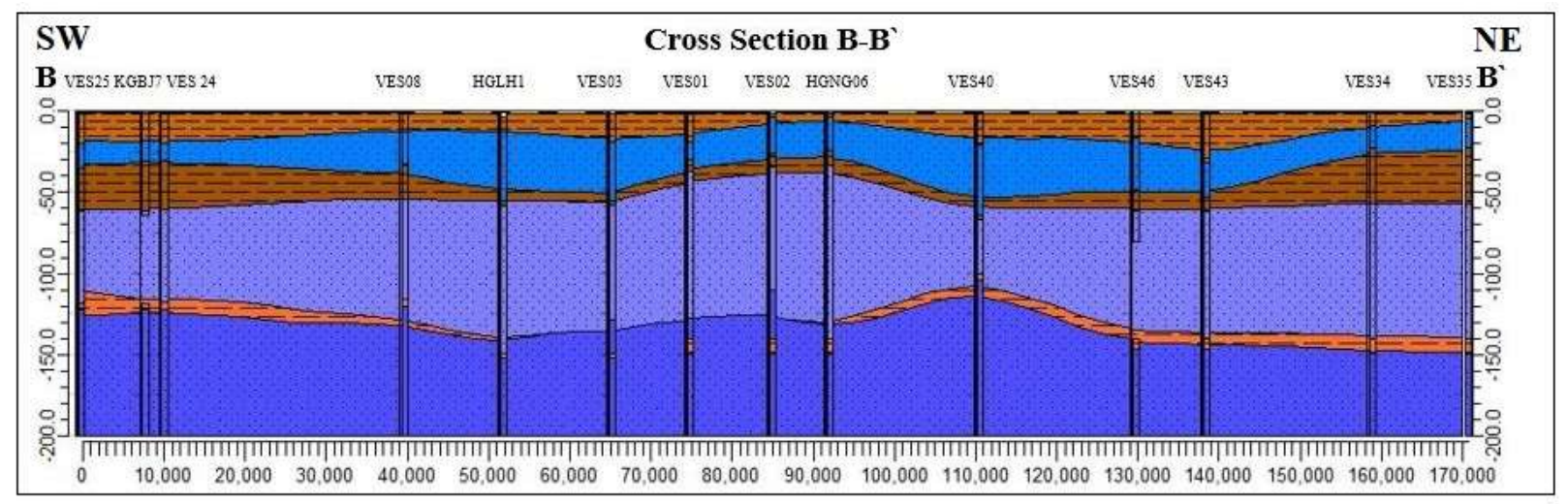

Fig. 8: Geo-electric cross-section along line B-B

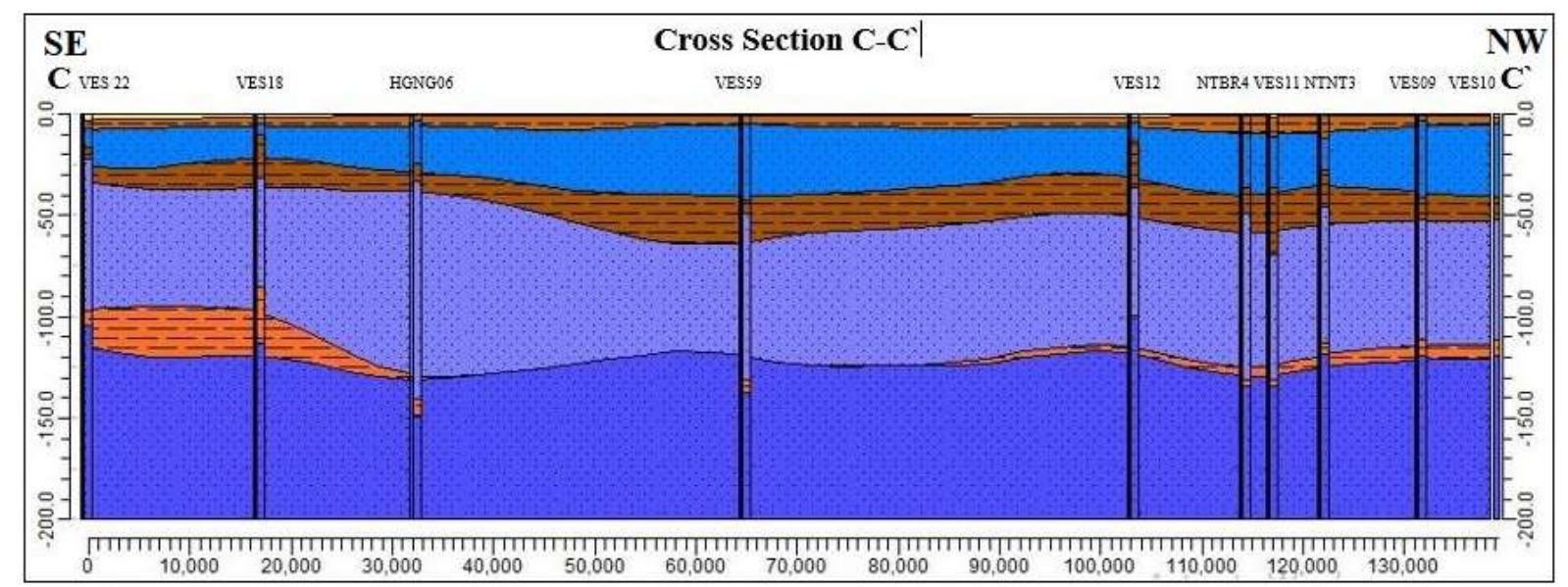

Fig. 9: Geoelectric cross-section along line C-C

identified layer is Aquifar-3 thickness of which couldn't be identified but may continue below observation depth.

\section{Interpretation of geoelectric cross-section of the study area along $C-C$}

Geoelectric cross sections along line C-C ' (Fig. 9) is run from SE-NW corner of the study area. The top layer is composed of silty clayey soil and is followed by Aquitard-1. Aquitard-1 is thin and continuous in throughout the section. Aquitard-1 is underlain by Aquifer-1, which is thick in the middle part of the section. The following hydrostratigraphic unit is Aquitard-2 of uniform thickness. Aquifer-2 with a more or less uniform thickness of more than $50 \mathrm{~m}$ is overlain by Aquitard-2. Aquifer-2 is underlain by Aquitard-3, which is thinner than the Aquitard-2 and in the middle it is very thin and hard to show in the cross section. The deepest identified layer is Aquifar-3 thickness of which couldn't be identified but has sufficient thickness and may continue below observation depth.

\section{Contour map}

The most important aquifer zone is aquifer-3. This layer is thicker than other aquifers because the lower boundary of this aquifer is not found upto $300 \mathrm{~m}$. The depth contour map along the upper boundary of Aquifer-3 (Figs. 10 and 11) shows maximum depth of this unit in the southern part of the survey

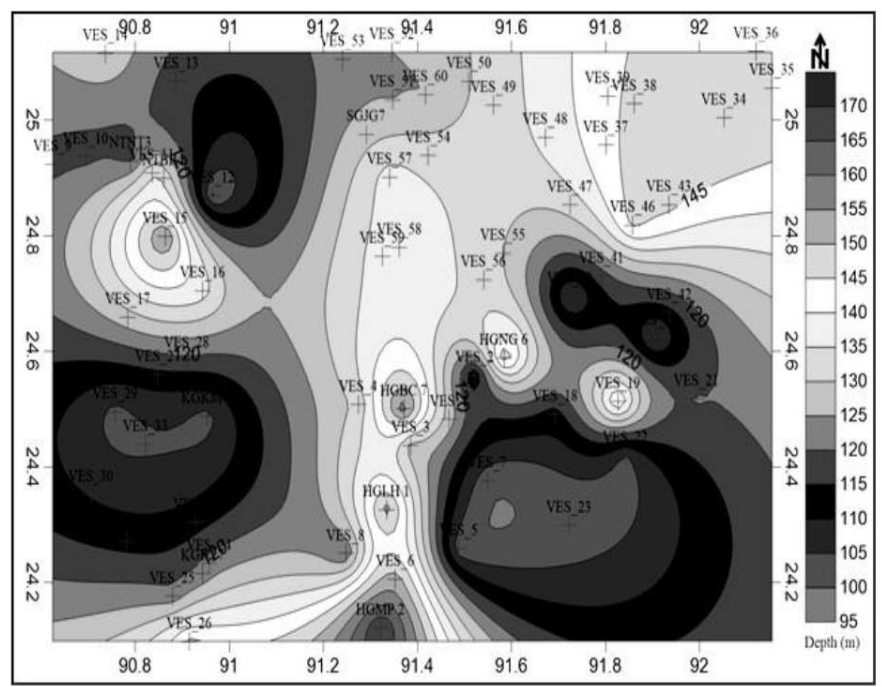

Fig. 10: Depth contour map along upper boundary of Aquifer-3 of the study area. (2D View) 


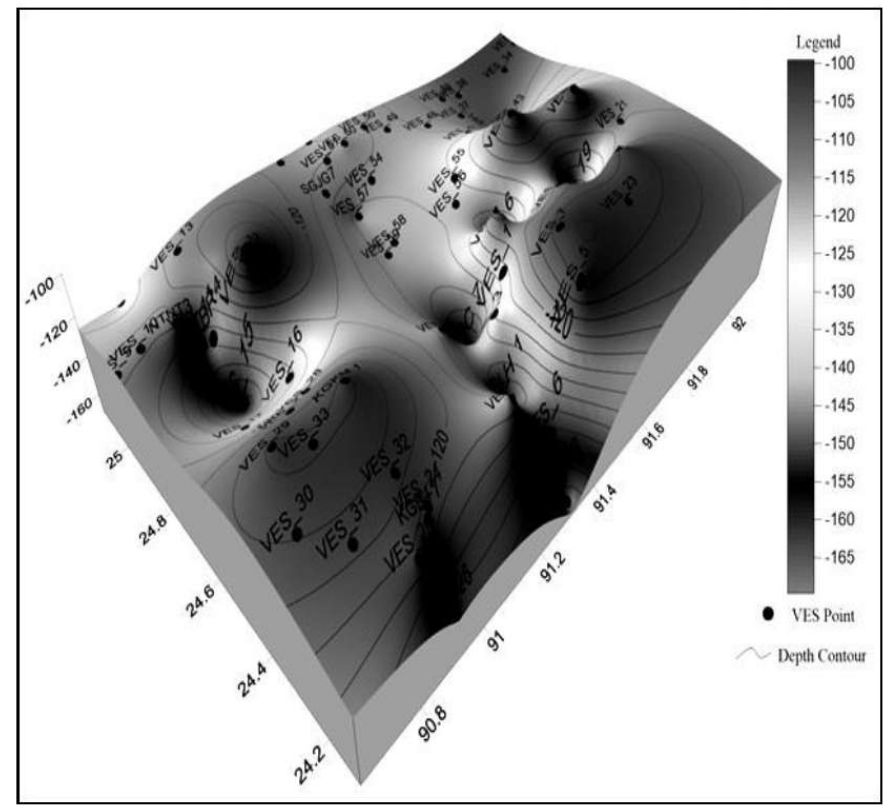

Fig. 11: Depth contour map along upper boundary of Aquifer3 of the study area. (3D View)

area. Maximum depth to the upper boundary of this unit is about $171 \mathrm{~m}$ at Madhabpur, Habiganj and minimum depth is about $100 \mathrm{~m}$ at Mohanganj, Netrokona. 3D view clearly indicates the

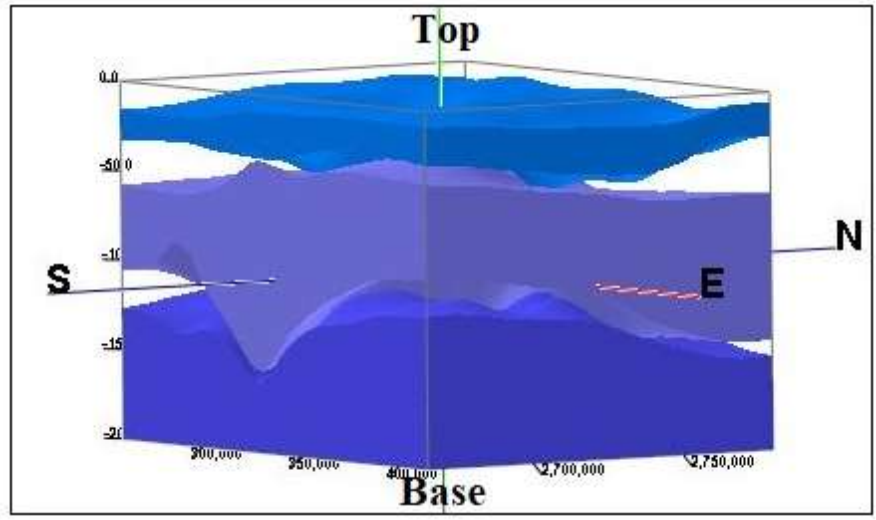

Fig. 12: 3D block diagram showing three aquifers

rapid rise of the aquifer boundary in the southern part of the study area (Figs. 12, 13).

\section{CONCLUSION}

Electrical resistivity sounding survey and existing bore hole data of the study area have been analyzed for the assessment of subsurface geological and hydrogeological conditions and water quality of the study area. Model parameters obtained through interpretation of the field sounding curves characterize the subsurface condition. The study area lies in the Surma basin consist of shallow and deep aquifers. The aquifers are recharged primarily by vertical percolation and floodwater.

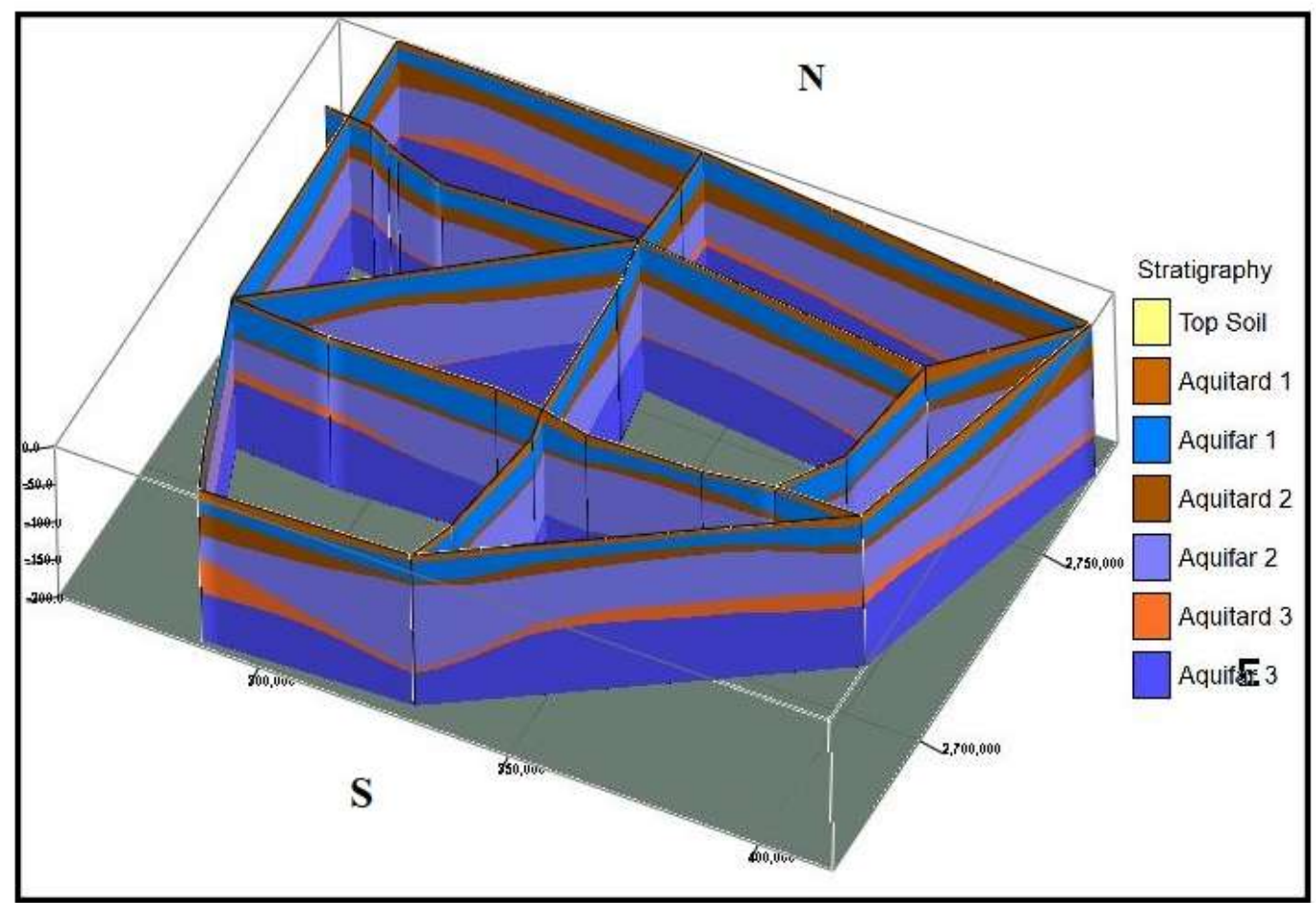

Fig. 13: Pseudo section of the study area 
The following conclusions are made considering the geology and hydrogeology of the area:

1. The top geoelectric unit is aquitard shows resistivity range of $11 \mathrm{ohm}-\mathrm{m}$ to about $24 \mathrm{ohm}-\mathrm{m}$ which is composed of clay or silty clay.

2. The next unit is Aquifer-1 (shallow aquifer) shows resistivity range of $25 \mathrm{ohm}-\mathrm{m}$ to $164 \mathrm{ohm}-\mathrm{m}$. The wide range of resistivity variation is mainly controlled by the variation in water quality of the unit. Considering the resistivity value, it can be said that the grain size of this sand layer is composed of fine to very fine sands, fine to medium sand, fine sand, clayey sands, medium sand and coarse sand. Borelog data also confirms the sand size variation in the sequence. Thickness of this unit varies from $4 \mathrm{~m}$ to $104 \mathrm{~m}$. Maximum thickness of Aquifer- 1 is about $104 \mathrm{~m}$ at Atpara, Kishoreganj and minimum thickness is about $4 \mathrm{~m}$ at Madan, Netrokona.

3. Aquifer-2 also shows the same resistivity range. Thickness of this unit varies from $3 \mathrm{~m}$ to $135 \mathrm{~m}$. Maximum thickness of Aquifer-2 is about $135 \mathrm{~m}$ at Madhabpur, Habiganj and minimum thickness is about $3 \mathrm{~m}$ at Bajitpur, Kishoreganj.

4. The deep aquifer, Aquifer-3, the base of which couldn't not be identified. Maximum depth of the lower boundary of this unit is about $171 \mathrm{~m}$ at Madhabpur, Habiganj and minimum depth is about $100 \mathrm{~m}$ at Mohanganj, Netrokona.

5. Aquifers containing saline water shows low resistivity value in the range of clay resistivity or even less. In this case direct information about the texture of the formation or the water quality of the formation water is required. At Madan, Netrokona low resistivity value of about 7 ohm-m below 107 $\mathrm{m}$ depth is found against a fine to medium sand layer (from borelog data) suggesting saline formation water.

\section{REFERENCES}

Serres, Y. F., 1969, Resistivity prospecting in a united Nation Groundwater project of Western Argentina, Geophysical Prospecting, 17 pp 449-467. https://doi.org/10.1111/j.1365-2478.1969.tb01989.x

UNDP., 1982. Groundwater Survey, The hydrogeological Condition of Bangladesh. UNDP Technical Report, DP/UN/BGD-74-009/1.

Woobaidullah, A.S.M. and Uddin, M.Z., 2011, Geoelectric resistivity sounding for deciphering hydrogeology and locating deep tubewell installation sites in Pouroshava area of Bagerhat, Bangladesh, Jour. Nepal Geol. Soc., v. 42, pp. 99-108.

Woobaidullah, A.S.M., Rahman, M., and Arndt, R., 1996, Electrical survey for groundwater exploration in the coastal belt of Satkhira, north-west Bangladesh, Jour. Geologiche Bundes Anstalt, Austria, 127-137.

Woobaidullah, A.S.M., Rahman, M., and Uddin, M.Z., 2014, Evaluation of hydrogeological condition through vertical electrical soundings survey at Manikganj Pourashava, Manikganj, Central part of Bangldesh, Bangladesh J. Sci. Res., v. $27(2), \quad$ p. $109-120$. https://doi.org/10.3329/bjsr.v27i2.26229

Woobaidullah, A.S.M., Ahmed, K.M., Hasan, M.A., and Hasan, M.K., $\quad 1998, \quad$ S a lin e ground water management in Manda Upazila of Naogaon District, NW Bangladesh, J. Geol. Soc. India, 51 January: 49-56.

Woobaidullah, A.S.M., Hasan, M.A., Reza, H., and Noor, A., 1994, An analysis of resistivity sounding data for groundwater exploration in Dumdumia-Nayapara, Teknaf, Dh. Univ. Jour. of Science, v. 42 (2), pp. 229-234. 